\title{
Development of a 100-Watt-Scale Beta-Type Low Temperature Difference Stirling Engine Prototype
}

\author{
Matthias Lottmann ${ }^{1}$, Zachary de Rouyan ${ }^{1}$, Linda Hasanovich ${ }^{1}$, Steven Middleton ${ }^{1}$, \\ Michael Nicol-Seto ${ }^{1}$, Connor Speer ${ }^{1}$, and David Nobes ${ }^{1 *}$ \\ ${ }^{1}$ University of Alberta, Department of Mechanical Engineering, 9211116 Street NW, \\ Edmonton, Alberta, Canada T6G 1H9
}

\begin{abstract}
This paper documents the ongoing design process of a Stirling engine prototype for a source temperature of $95{ }^{\circ} \mathrm{C}$, aiming to achieve shaft power on the order of 100 Watts. The engine will serve to produce experimental data for the validation of a numerical low temperature Stirling model. The higher-level motivation is to assess the technical and economical potential of producing power from abundant sources of low temperature heat by using Stirling engines. Design decisions are governed by the goals of minimizing energy losses and maximizing the variability of operating points through variable heat exchanger geometry, compression ratio and charge pressure. The resulting design is a beta engine with a total gas volume around 100 liters. It features displacer and power pistons in a combined cylindrical working space and a mechanism using pivoting links similar to a bellcrank. The stroke of the power piston is adjustable while maintaining a constant top dead center position. A component critical for friction is the power piston seal, for which a low friction rolling seal and a conventional sliding seal were considered. As of June 2021, the development is at an advanced state and the first set of components are entering production.
\end{abstract}

\section{Introduction}

There is a significant energy resource in the form of low temperature (LT) heat that is widely available but currently not being utilized. This refers to heat sources with temperatures of $150{ }^{\circ} \mathrm{C}$ or lower. Much of this energy potential exists from geothermal heat sources, which are available in great capacity within the province of Alberta, Canada [1]. In addition, LT heat is commonly discarded as a by product of energy intensive industries. These sources of sustainable energy have so far never played a role because their low exergy makes them inefficient to process compared to higher temperature sources. This causes their utilization to be not economically desirable compared with conventional sources.

The urgent need to transform our energy landscape towards sustainability is sparking research to create technologies which can exploit these unconventional energy sources. The Dynamic Thermal Energy Conversion Lab (DTECL) at the University of Alberta is

\footnotetext{
*Corresponding author: dnobes@ualberta.ca
} 
researching Low Temperature Difference Stirling Engines (LTDSEs) to utilize LT heat. The overarching goal is to assess the feasibility of LTDSEs as part of the power supply infrastructure on a broad scale.

An experimental engine ('2021 prototype') is currently in development that will advance the research from a small to an intermediate scale $(100-1000 \mathrm{~W})$. This paper outlines the development process of this prototype including motivation and goals, discussion of significant design decisions and strategies to achieve those design goals, and a rundown of the current status of the design. The LTDSE presented in this work is currently (June 2021) in the late development stage and manufacturing of the first set of components is about to begin. Therefore the as-built engine may be subject to only minor changes compared to the designs shown here.

\subsection{Review of Past Research}

Apart from Stirling engines, the Organic Rankine Cycle (ORC) is a competing technology for power generation from LT heat. A comparison of these two technologies is offered by Speer [2]. The following is a summary of the relevant research carried out by DTECL so far and the lessons learned that are going to shape the design goals for the 2021 prototype.

Experimental research so far has been focused on small scale lab engines with shaft power $P_{\text {shaft }}<10 \mathrm{~W}$ that were mostly of the gamma type. These were used to gain a basic practical understanding of the parameters that govern a LTDSE. To initiate this research, an existing design of a high temperature gamma engine was fitted with different modifications aimed at improving its performance when operated at lower temperatures $[3,4]$. These modifications were a reduction of dead volume, downsizing of the power piston to reduce the compression ratio $(C R)$ and enlarging the buffer volume to reduce forced work. Experiments showed that neither of the changes enabled the machine to achieve considerable shaft power. This was related to the mechanical friction being too strong and negating most of the indicated cycle work, as well as lacking heat exchanger performance [3].

A set of custom gamma engine prototypes were designed and built [5] to operate with atmospheric buffer pressure and temperatures $T_{\text {source }}=95^{\circ} \mathrm{C}, T_{\text {sink }}=5^{\circ} \mathrm{C}$. The largest of these has a swept volume on the order of $10 \mathrm{~L}$ and was used to experimentally determine optimum values for working parameters such as $C R$ and phase angle. It was found that a phase angle of $90^{\circ}$, which is common in piston-displacer engines, should be used for LTDSE and varying the phase angle does not yield performance improvements.

The same engine was equipped with a gearset drive mechanism which allows for nonsinusoidal motion kinematics on displacer and power pistons [6,7]. Both pistons were dwelled at the top dead center (TDC) and bottom dead center (BDC) positions to make piston motion more discontinuous and shape the indicator diagram more similar to the ideal Stirling cycle. This did result in the expected change of the indicator diagram and increase of indicated work. However, it did not result in the expected increase of power because the increased friction associated with this motion, due to the pistons moving at higher velocities than in sinusoidal motion, eliminated any increase in indicated cycle work. It was also observed that a sawtooth motion profile with constant piston velocity caused an increase in output power.

Low temperature alpha type engines were also investigated and tested [8] but were found to have poor performance characteristics as they did not yield positive power. This was related to the amount of forced work traveling through the mechanism being larger for a setup with expansion and compression piston than with displacer and power piston. This flaw makes the alpha layout undesirable for LTDSE.

These findings show an important paradigm that appears to be a useful rule when designing LTDSEs: Performance is dominated by energy losses and minimizing these losses 
is key to achieving a good shaft power. The indicated cycle work is inherently limited by the Carnot efficiency and thereby the temperature ratio, and it is difficult to increase the indicated work (e.g. through piston dwelling, increasing heat exchanger size etc.) without also introducing more friction or dead volume. Instead, it is more effective to improve performance by minimizing losses and thus turning more of the indicated work into shaft work.

A numerical model which can reliably predict the performance of LTDSEs and similar thermodynamic machines would be desirable. This is only possible by accurately simulating the loss mechanisms that have a strong effect at low temperatures. First and second order models do not model these losses precisely enough, and existing higher order models are not openly available [9]. To fill this gap, a custom third order one-dimensional model has been developed specifically for the low temperature regime [9]. Providing the empirical data for the validation of this model is the main objective of the 2021 prototype. Hence this engine must be designed keeping in mind the lessons learned from previous engines as outlined above, as well as the capability to produce data at diverse operating points to validate the model extensively. All the data will be published in detail, so it can serve as a benchmark for LTDSE researchers.

\section{Goals and Requirements for the Prototype}

A number of goals are set out that will guide the development process. The physical engine size is estimated using the isothermal model, and required features are derived from the experimental purpose of the machine.

\subsection{Engine Volume Size}

Before making any decisions on the engine geometry, a rough estimate for the engine volume is obtained through isothermal analysis, following the Schmidt model described by Senft [10]. As inputs, the following parameters are defined or estimated.

\subsubsection{Target Engine Power}

The overall scale of the engine is defined by its targeted shaft power output. This target needs to be defined rather arbitrarily, but is required as a starting point for the design process. In this case, the main factors to determine an appropriate goal are:

- The model that is to be validated will be used to predict the performance of large potential engines on the kilowatt scale. Ideally it would be validated with data from an engine of similar power scale. Data from previous prototypes comes from a much smaller scale $(<10 \mathrm{~W})$ and is in some cases subject to large errors because of measurement uncertainties. Therefore the 2021 prototype power should be as high as possible for data to be comparable to the kilowatt scale and to produce accurately measurable outputs (pressure, power, torque).

- However, size is limited by budget; lab space; lab power supply capacity for heating and cooling; and difficulties in manufacturing or assembly, for example handling of large components.

Based on these limitations, a target of $P_{\text {shaft }}=100 \mathrm{~W}$ at atmospheric charge pressure and at a frequency of $f=1 \mathrm{~Hz}$ was set. Engine frequency is difficult to predict in the early design stage as it depends on heat exchanger performance and overall friction in the engine. From experience with previous engines it is estimated that given sufficient heat exchanger performance, the prototype will reach its maximum power at $1 \mathrm{~Hz}$ or higher. 


\subsubsection{Heat Source \& Sink Temperatures}

Liquid water at $95{ }^{\circ} \mathrm{C}$ and $5{ }^{\circ} \mathrm{C}$ has been used as heating and cooling medium in past experiments. The same approach will be followed with the 2021 prototype. The use of oil to reach higher temperatures is not necessary in the scope of this research and would make handling the liquid more difficult compared to water. Because heating and cooling power are limited with the current lab equipment, the heat sink could potentially be run with cold tap water that is discarded after passing through the heat exchanger, instead of being cycled through a cooling bath. This will increase the sink temperature to about $10{ }^{\circ} \mathrm{C}$.

\subsubsection{Estimated Working Space Temperatures}

Real engine gas temperatures change continuously during the cycle. The isothermal model assumes a hot and a cold volume space with constant temperatures. These temperatures must be estimated based on how much temperature change the heat exchangers are expected to achieve. Measured temperatures are known from the most recent engine that operated with equivalent source and sink temperatures, and heat exchange is expected to improve in the 2021 prototype over previous ones because heat exchanger volume will increase significantly. On this basis, working space temperatures are expected in the ranges of $T_{h}=[75,85]^{\circ} \mathrm{C}$ and $T_{c}=[15,25]^{\circ} \mathrm{C}$.

\subsubsection{Volume Size Scaling}

Additional input parameters that must be estimated are:

- Volume ratios $V_{d} / V_{s w d}$ and $V_{H X} / V_{s w d}$

- Mechanism Effectiveness $E$

where $V_{d}$ is the dead volume (excluding heat exchangers), $V_{s w d}$ is the displacer swept volume, and $V_{H X}$ is the volume of the heat exchangers. Mechanism Effectiveness is a concept developed by Senft [10]. It simplifies all losses, which reduce the indicated cycle work to the shaft work, into a single nondimensional parameter $E$. Out of all energy moving through the mechanism between the power piston and the flywheel, a fraction $(E)$ is transferred and the remaining $(1-E)$ is lost to friction. With these parameters the isothermal model can estimate an optimal $C R$, which defines the power piston swept volume $\left(V_{s w p}\right)$. All volume spaces are then scaled proportionally to match the shaft power goal defined in section 2.1.1. Three different scenarios with different estimates of the inputs are analyzed as shown in Table 1. In scenario 1 the engine underperforms its expectations, while in scenario 3 it performs above expectations. Between these extremes is the performance range that the prototype will most likely fall within. Scenario 2 is a realistic middle ground and its results will be used as the initial design size goal. 
Table 1: Input parameters for engine sizing using isothermal analysis

\begin{tabular}{|l|l|l|l|l|l|}
\hline & \multicolumn{5}{|c|}{ Input Parameters } \\
\hline Scenarios & $\boldsymbol{V}_{\boldsymbol{d}} / \boldsymbol{V}_{\boldsymbol{s w \boldsymbol { d }}}$ & $\boldsymbol{V}_{\boldsymbol{H} \boldsymbol{X}} / \boldsymbol{V}_{\boldsymbol{s} \boldsymbol{w} \boldsymbol{d}}$ & $\boldsymbol{T}_{\boldsymbol{h}}\left[{ }^{\circ} \mathrm{C}\right]$ & $\boldsymbol{T}_{\boldsymbol{c}}\left[{ }^{\circ} \mathrm{C}\right]$ & $\boldsymbol{E}$ \\
\hline 1 - Pessimistic & 0.4 & 0.4 & 75 & 25 & 0.75 \\
\hline 2 - Realistic & $\mathbf{0 . 3}$ & $\mathbf{0 . 3 5}$ & $\mathbf{8 0}$ & $\mathbf{2 0}$ & $\mathbf{0 . 8}$ \\
\hline 3 - Optimistic & 0.2 & 0.3 & 85 & 15 & 0.85 \\
\hline
\end{tabular}

Table 2 shows the resulting engine volume estimates from the isothermal model. Following the realistic scenario, the total gas volume of the engine will be on the order of $90 \mathrm{~L}$ with the displacer piston sweeping about $40 \mathrm{~L}$ of that. Note that the compression ratio suggested by this model is high compared to the values found by studying experimental data from numerous LTDSE as done by Stumpf [5]. This indicates the fact that the isothermal model overestimates the performance of real engines because it accounts for losses only very coarsely. A real engine with these dimensions would likely not achieve the target shaft power. This result should be used only as a rough size to design for.

Table 2: Results from engine scaling to $100 \mathrm{~W}$ shaft power using isothermal analysis

\begin{tabular}{|l|l|l|l|l|l|l|}
\hline & \multicolumn{6}{|c|}{ Results } \\
\hline Scenarios & Optimal $\boldsymbol{C R}$ & $\boldsymbol{V}_{\boldsymbol{s w \boldsymbol { d }}}[\mathrm{L}]$ & $\boldsymbol{V}_{\boldsymbol{s w p}}[\mathrm{L}]$ & $\boldsymbol{V}_{\boldsymbol{H} \boldsymbol{X}}[\mathrm{L}]$ & $\boldsymbol{V}_{\boldsymbol{d}}[\mathrm{L}]$ & $\boldsymbol{V}_{\text {total }}[\mathrm{L}]$ \\
\hline 1 - Pessimistic & 1.209 & 76 & 28.6 & 30.4 & 30.4 & 165.4 \\
\hline 2 - Realistic & $\mathbf{1 . 3 3 5}$ & $\mathbf{4 0 . 5}$ & $\mathbf{2 2 . 4}$ & $\mathbf{1 4 . 2}$ & $\mathbf{1 2 . 2}$ & $\mathbf{8 9 . 3}$ \\
\hline 3 - Optimistic & 1.549 & 22.5 & 18.5 & 6.75 & 4.5 & 52.3 \\
\hline
\end{tabular}

\subsection{Modular Heat Exchangers}

A main research question to be tackled is the effect of different heat exchanger geometries and sizes on LTDSE performance. All previous prototypes had their heat exchangers integrated into the engine body so that it was not possible to test different heat exchanger shapes in one engine. For the 2021 prototype the heat exchangers will not be or limited in size and shape by the engine structure but will be designed as a separate module. These modules will have their own support structure and connect to the engine volume through plenums. They can then be exchanged or modified without disassembly of the engine body.

The usefulness of regenerators in LTDSE is uncertain since they are less effective and cause more flow losses in the low temperature regime. Modular heat exchangers will allow various regenerator materials easily and investigate this question.

\subsection{Variable Compression Ratio}

For any operating point of a Stirling engine there is an optimal $C R$ that yields maximum shaft power. The $C R$ optimum is a complex product of engine performance parameters, especially heat exchanger performance and friction losses. To model these accurately is 
precisely the goal of our numerical model. Therefore, predicting this optimum will be an important measure for the validation because it gives an image of how well the model performs in its key area.

$C R$ will be adjustable so that it can be optimized for a given engine working point. The analysis by Stumpf [5] on the EP-1 and other engines suggests a range for the optimal CR based on source and sink temperatures. Combined with the estimate from isothermal modeling, a target range of $C R=[1.2,1.4]$ is reasonable for optimization as well as for manufacturability of a mechanism with that range.

\subsection{Variable Charge Pressure}

The engine charge pressure will be adjustable between $1 \mathrm{~atm}$ and $10 \mathrm{~atm}$. This allows the significant change of the indicator diagram, and mechanics of flow friction and heat transfer and will be a key variable for model validation. The engine working spaces as well as the mechanism will need to be integrated into pressure bearing units, which makes compact designs desirable.

\subsection{Minimize Mechanical Friction}

Following the verdict of our past research work (section 1.1), the overall objective to eliminate losses wherever possible will take an important role in every aspect of the design. This paradigm will especially influence the discussions related to mechanism and seals.

\section{Engine Layout \& Mechanism Design}

The layout and mechanism must be chosen to fulfill the requirements outlined in section 2. Most mechanisms are only suitable for a specific layout. Therefore, these design decisions are closely connected.

An alpha layout is excluded from consideration for reasons discussed in section 1.1. Two layouts were compared side by side which can be built to fulfill all requirements. These are a parallel gamma layout with pistons side by side as shown in Figure 1(a), and a beta layout which features both pistons sharing their motion axis and working space seen in Figure 2(a).

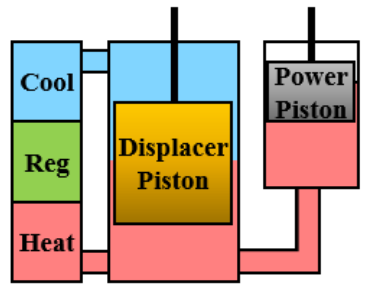

(a)

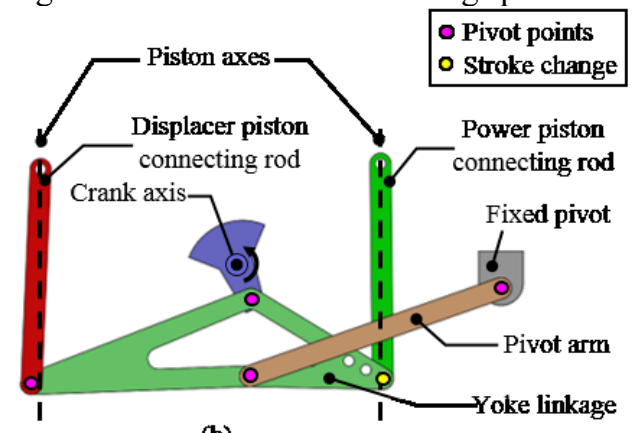

(b)

Figure 1: Parallel gamma engine layout (a) and Ross Yoke mechanism (b) 


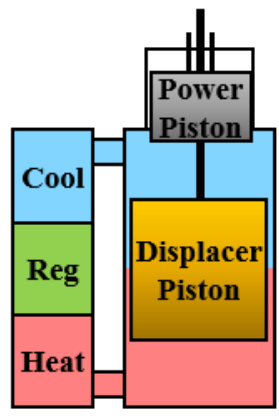

(a)

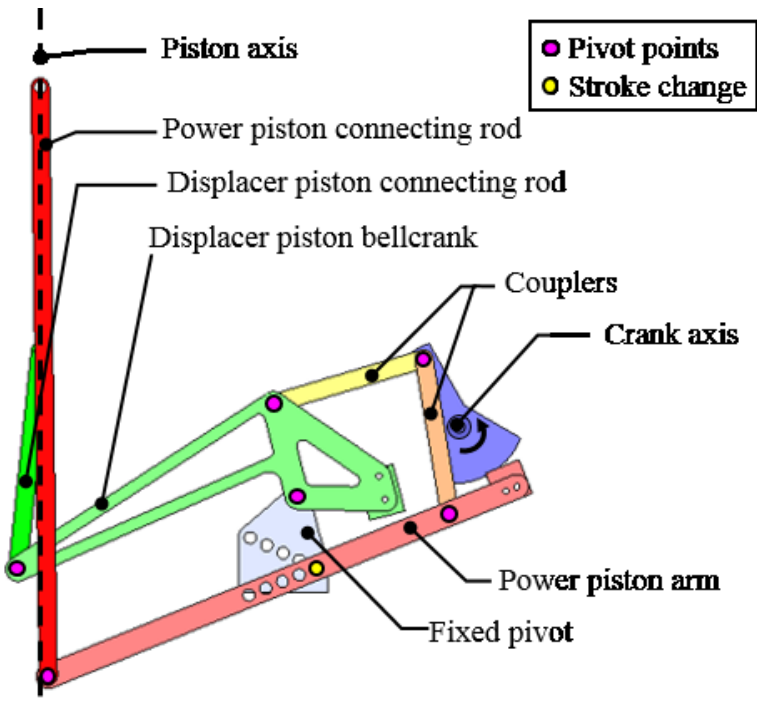

(b)

Figure 2: Beta engine layout (a) with coaxial bellcrank mechanism (b)

A wide range of mechanisms including slider crank, scotch yoke, Ross yoke, rhombic drive, bellcrank linkages, camshafts, rocker arms, and some axial motion generators such as swashplate, barrel cam and leadscrew were compared using the following criteria:

- Must be able to vary power piston stroke for changing $C R$ while maintaining TDC, with as little effort as possible

- Avoid high complexity (number of parts, assembly)

- Compactness (in order to fit into a compact crankcase)

- Mechanical friction: number of load-carrying bearings, especially sliding contacts (e.g. scotch yoke)

- Side load angle between piston axes and connecting rods are small

The side load angle is the angle between a connecting rod and the piston axis that it connects to. This angle varies throughout the engine cycle. The maximum angle is much larger in simple mechanisms (e.g. slider crank) than in others which apply only little rotation to the connecting rod (e.g. bellcrank). The greater the side load angle, the stronger is the radial force (side load) applied to the piston by the mechanism. This side load must be absorbed by the linear guide of the piston, which is usually a sliding linear bushing. The sliding contact causes friction and results in a loss of shaft power. Therefore, a mechanism should be designed to ensure a small side load angle.

For both competing layouts a suitable mechanism was chosen. These are a Ross yoke for the gamma layout (Figure 1(b), [12]), and a bellcrank linkage for the beta layout (Figure 2(b), adapted from Senft and Senft [11]). Both mechanisms

- Can vary piston stroke by changing the position of one pivot point (see Figure 1, Figure 2),

- Have small side load angles throughout the cycle,

- Have no sliding contacts, therefore they can be considered equal in terms of friction. However, the beta-bellcrank combination has several advantages that affect manufacturing effort and performance: 
- The beta setup contains both pistons in a shared engine body and on the same axis. A single pressure vessel (cylinder) can house the engine working volume, reducing the number of pressure-bearing structures.

- Thanks to the shared piston axis, the bellcrank mechanism is more compact and will fit into a smaller pressure-bearing crankcase.

- The coaxial pistons of the beta can use a shared linear guide like a central guide rod.

- The beta layout allows for the stroke of the pistons to overlap during part of the cycle. This reduces the overall engine volume and increases the pressure swing without shrinking the working spaces. However, the possible amount of overlap depends heavily on the difference between power piston and displacer piston stroke.

- The gamma setup requires air ducts between the working spaces, which increases dead volume and flow friction. These are not required in a beta layout as the working spaces are directly connected.

With these considerations the beta layout and bellcrank mechanism are considered the best choice for LTDSE and this concept is the basis for the detailed development of our prototype.

\section{Current Design Status: Assemblies and Components}

The following sections give an overview of the main sections of the prototype design as of late June 2021. In Table 3 all the operating parameters that are known for the current state of design are summarized.

It should be noted that, comparing the $C R$ range of the current design with that proposed in section 2.3, the maximum $C R$ should be increased by increasing power piston swept volume or reducing the size of other gas volumes.

Table 3: Summary of engine design specifications

\begin{tabular}{|c|c|c|}
\hline Location & Parameter & Value \\
\hline \multirow{3}{*}{ Displacer Piston } & Outer Diameter & $457 \mathrm{~mm}$ (18 inch) \\
\hline & Stroke & $254 \mathrm{~mm}$ (10 inch) \\
\hline & Swept Volume & $41.2 \mathrm{~L}$ \\
\hline \multirow{3}{*}{ Power Piston } & Outer Diameter & $305 \mathrm{~mm}$ (12 inch) \\
\hline & Stroke & $25 \ldots 254 \mathrm{~mm}(1 \ldots 10 \mathrm{inch})$ \\
\hline & Swept Volume & $1.8 \ldots 18.1 \mathrm{~L}$ \\
\hline Heat Exchangers & Gas Volume (aprx.) & $20 \mathrm{~L}$ \\
\hline $\begin{array}{l}\text { Other volumes } \\
\text { (Regenerator, dead } \\
\text { volume) }\end{array}$ & Gas Volume (aprx.) & $20 \mathrm{~L}$ \\
\hline Central Guide Rod & Diameter & $50 \mathrm{~mm}$ \\
\hline \multirow{6}{*}{ General } & Compression Ratio $(C R)$ aprx. & $1.022 \ldots 1.223$ \\
\hline & Phase Angle & $90^{\circ}$ \\
\hline & Source / Sink Temperature & $95^{\circ} \mathrm{C} / 5^{\circ} \mathrm{C}$ \\
\hline & Charge / Buffer Pressure & $1 \ldots 10 \mathrm{~atm}$ (absolute) \\
\hline & Working Gas & Air \\
\hline & Expected Engine Frequency Range & $0.5 \ldots 3 \mathrm{~Hz}$ \\
\hline
\end{tabular}

Figure 3 shows the overall assembly of all functional engine sections missing only the support structure that will carry the weight of the machine. The piston axis is in a horizontal orientation to allow easier handling (i.e. taking engine apart, moving it around) and to avoid 
the weight of the pistons acting on the mechanism. A cylinder forms the single pressure vessel that houses both pistons. The mechanism is suspended in a box-shaped crankcase. It connects to a flywheel for which the moment of inertia specification has yet to be determined. Heat exchangers and regenerator are housed in two external modules that are independent of the working space and attach to the cylinder through clamped ports.

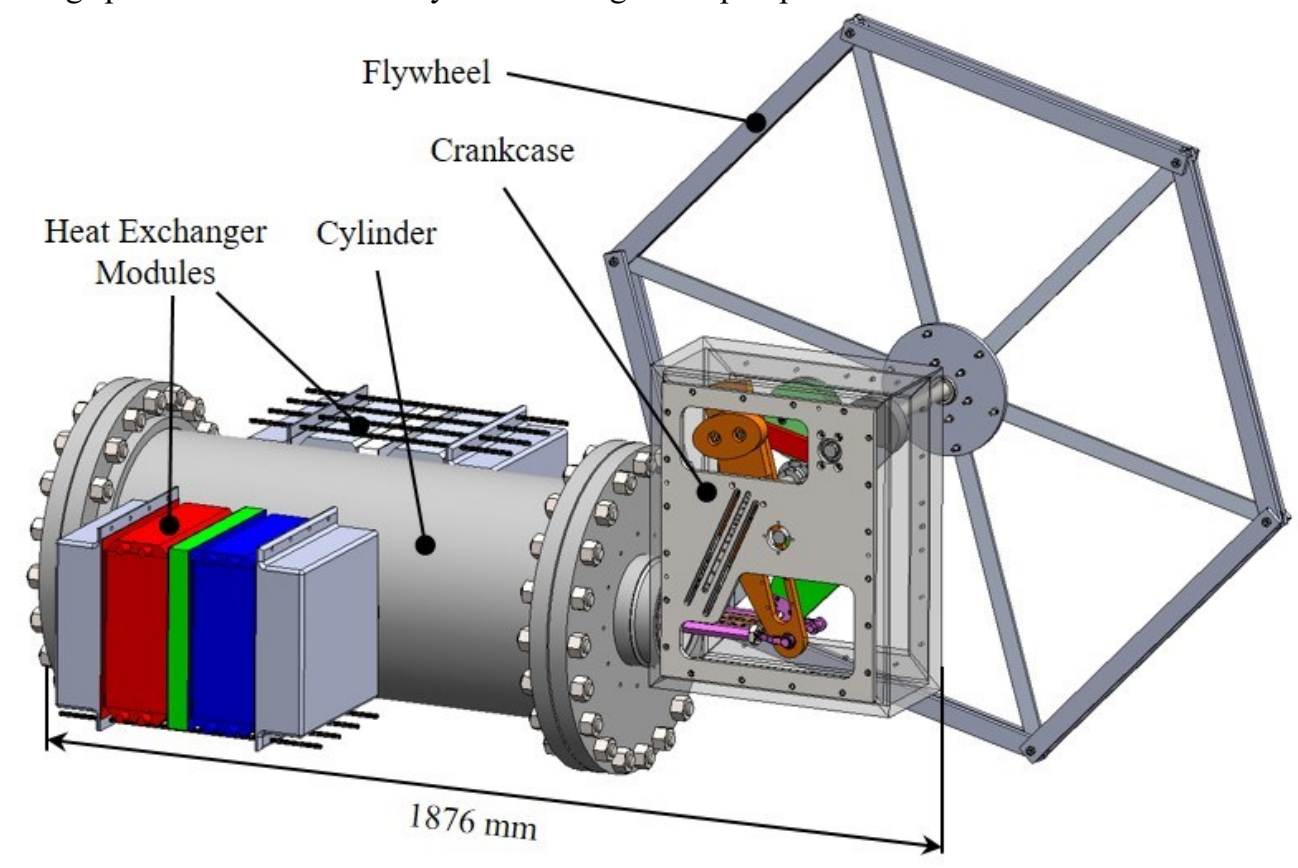

Figure 3: Solid model of overall engine assembly

\subsection{Power Piston Location}

It is important to note that the power piston, as seen in Figure 2(a) and Figure 3, is connected to the cold side of the working space. The reasons for this are:

- Due to the phasing of the pistons, stroke overlap (see section 3) can only be utilized when the power piston is positioned on the cold side.

- Lower temperature at the power piston allows to use non-heat-resistant materials (polymers, elastomers), especially for the piston seal which is critical for performance.

- The numerical model [9] was used to estimate whether the power piston position affects engine performance. No notable difference was observed.

\subsection{Mechanism and Crankcase}

Figure 4 displays the crankcase and mechanism components in detail. The bellcrank mechanism introduced in section 3 operates within a rectangular crankcase. There is one bellcrank situated at the center plane of the crankcase, and two piston arms symmetrically from the center plane of which only one is shown. All pivot points have ball or needle roller bearings to minimize friction. Both linkages are fitted with counterweights that aim to eliminate the shaking forces caused by the acceleration of the pistons. The outside frame of the case consists of welded steel C-channel. All mechanism components are suspended on and located by the rotating crankshaft and two stationary pivot shafts. The crankcase acts as 
a pressure vessel when the engine operates at above-atmospheric buffer pressure. In that case, two seal plates (not shown) are mounted on either of the open sides and sandwich the crankcase, sealing it from the environment.

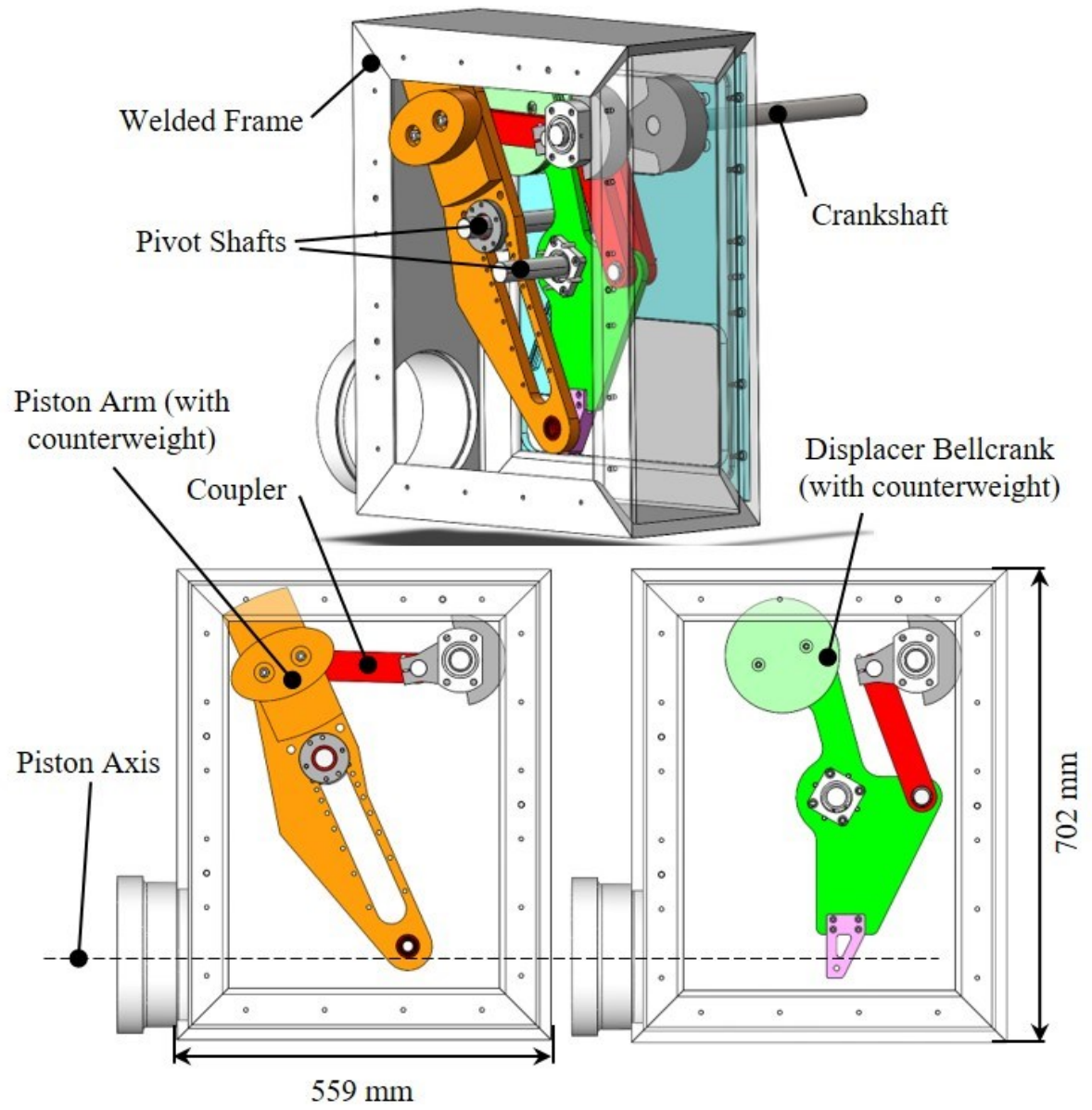

Figure 4: Crankcase containing mechanism. Top: Bellcrank and one piston arm installed (second piston arm not shown). Left: Piston arm only. Its current pivot point position corresponds to maximum stroke length. Right: Displacer bellcrank only.

\subsection{Power Piston Stroke Change Method}

The piston arm is a straight link that rotates about a pivot shaft located on the line between the arm's coupling points. Moving the pivot shaft along that line changes the ratio at which motion is translated between the coupling points. That changes the stroke length of the power piston which is coupled to the piston arm. The stroke is adjustable between 1 and 10 inches (25 to $254 \mathrm{~mm}$ ).

The location of the pivot shaft on the crankcase can be moved along a line that keeps the power piston TDC position constant while altering the stroke length. Figure 5 illustrates the motion of the piston arm between piston BDC and TDC positions for the largest and smallest possible stroke setting. The pivot shaft is mounted on the crankcase side plate and its position is changed along the visible line of holes. Note how at TDC the piston arm is in the same position independent of the stroke setting. 

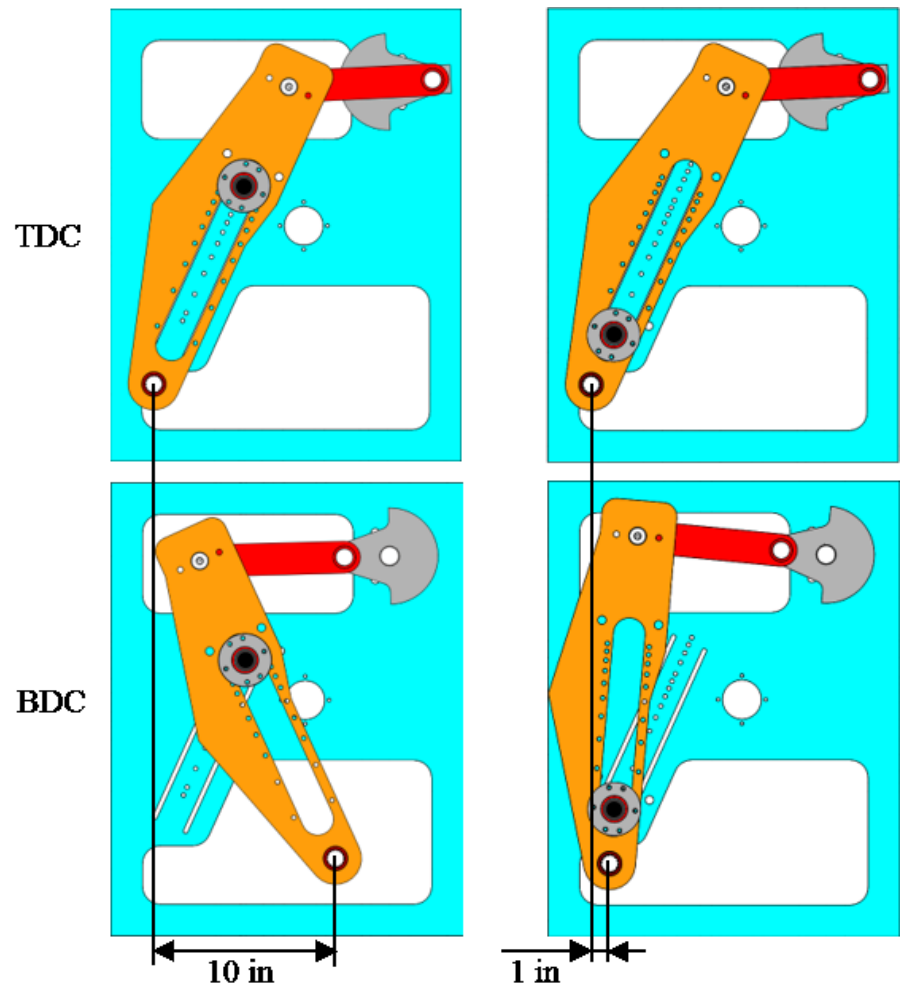

Figure 5: Illustration of stroke change method. Piston arm is shown in TDC and BDC positions when performing a stroke of 10 inches (left) and 1 inch (right). Red: Coupler, grey: crank web / crankshaft, blue: side plate of crankcase.

\subsection{Cylinder and Piston Guide}

A section cut view of the main cylinder body can be found in Figure 6. The working spaces are contained within a 20 inch $(508 \mathrm{~mm})$ OD tube. See Table 3 for piston and volume dimensions. Taking advantage of the coaxial pistons of the beta layout, a hollow, stationary guide rod acts as the linear guide for the displacer piston and can also act as guide for the power piston, depending on its type of seal (see section Power Piston Seal 4.5). The inside wall of the pipe will be fitted with a precision liner from insulating material in order to reduce heat conduction to the outside and to make the bore more cylindrical for the displacer piston.

\subsubsection{Displacer Piston}

The displacer piston rides on the outside of the guide rod and is operated through a push rod located inside the guide rod, which connects to the displacer bellcrank on the mechanism side. For the design of the displacer piston itself, numerous options including a hollow carbon fiber cylinder, a hollow metal design with domed ends and a rigid polyurethane foam cylinder as used in previous engines were considered. For a hollow or porous displacer, the pressure inside the displacer will equal the mean cycle pressure during operation and the displacer experiences significant pressure forces from the engine pressure swing. The goal is to design a displacer that withstands these stresses safely while being as lightweight as possible. The chosen design is made from a stack of thermal insulation foam sheets. This option has proven 
reliable in previous prototypes and can be very light because the moderate source temperature allows the use of relatively low-density foam.

The seal between the displacer piston and its bore is not critical regarding leakage as it only seals two sections of the working space from each other and it faces only a small pressure differential equal to the pressure drop across the heat exchanger module. A thin polymer sheet will be fixed between layers of the foam displacer to seal the appendix gap. This method has been observed to work well as a low-friction seal in other prototypes built by DTECL $[5]$.

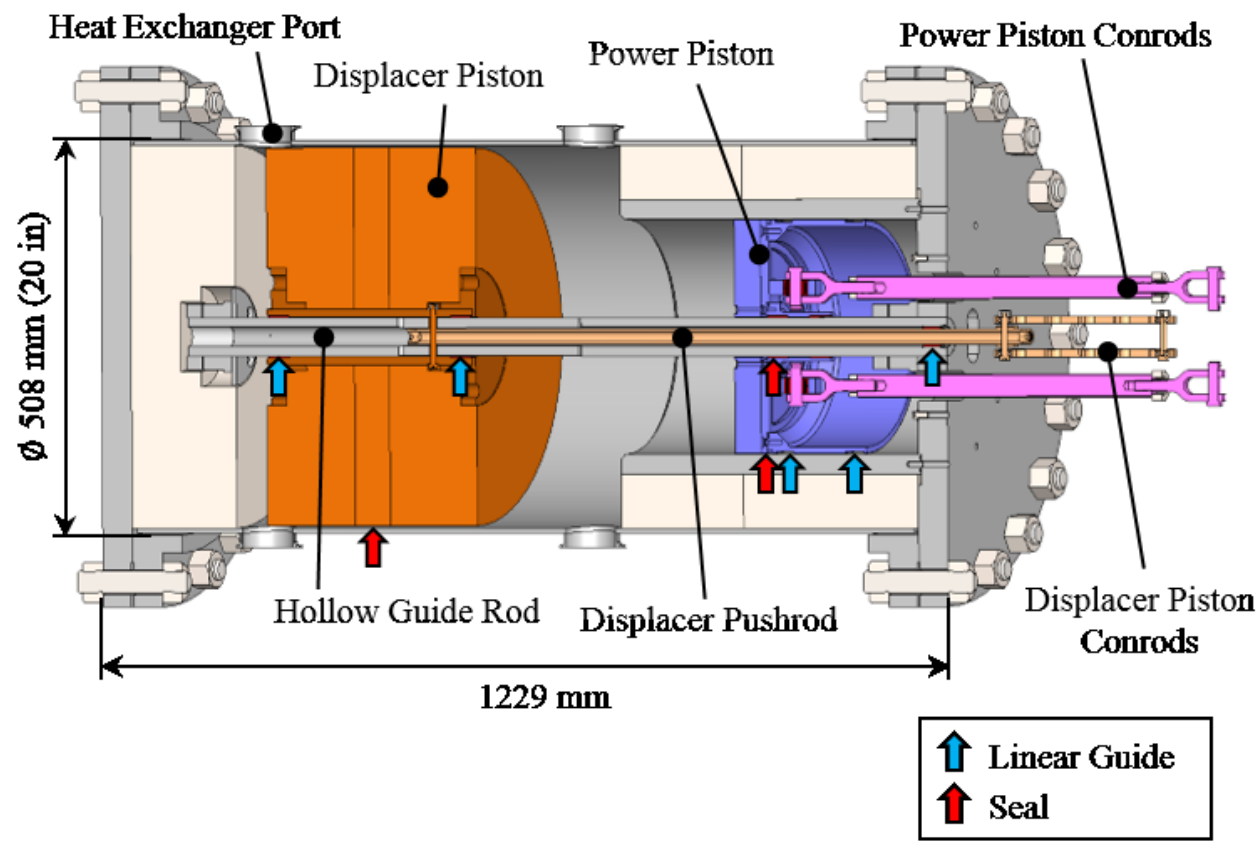

Figure 6: Section view of main cylinder containing both pistons and their working spaces. Linear guide and seal locations highlighted for the power piston using a sliding seal and being guided on the bore.

\subsection{Power Piston Seal}

The central objective when designing an LTDSE is minimizing frictional losses as described in section 1.1. This makes the power piston seal a critical component because of its potential to cause friction. See Table 4 for a comparison between the two piston seal options discussed in the following.

The piston seal faces a significant pressure difference between working space and buffer space, which for the 2021 prototype can reach a maximum of $\sim 2$ atm according to numerical results. When using a sliding seal such as a PTFE ring, a radial force is required between seal and bore which translates into sliding friction that is highly sensitive to said radial force. These seals are commonly used in applications like hydraulics where seal friction is negligible against a much larger pressure difference. PTFE sliding seals have operated in LTDSEs efficiently and shown high reliability [13], but it requires testing to fine tune the fit between seal and bore to achieve both sealing and minimal friction. Additionally, sliding seals usually require a precision bore with a polished surface, which is a cost driver. They also must be guided by the bore to maintain alignment, and thus the concept of using a single rod to guide both pistons (see section 4.4) cannot be realized with a sliding piston seal. 
Table 4: Comparison of Rolling Diaphragm Seal and Sliding Seal

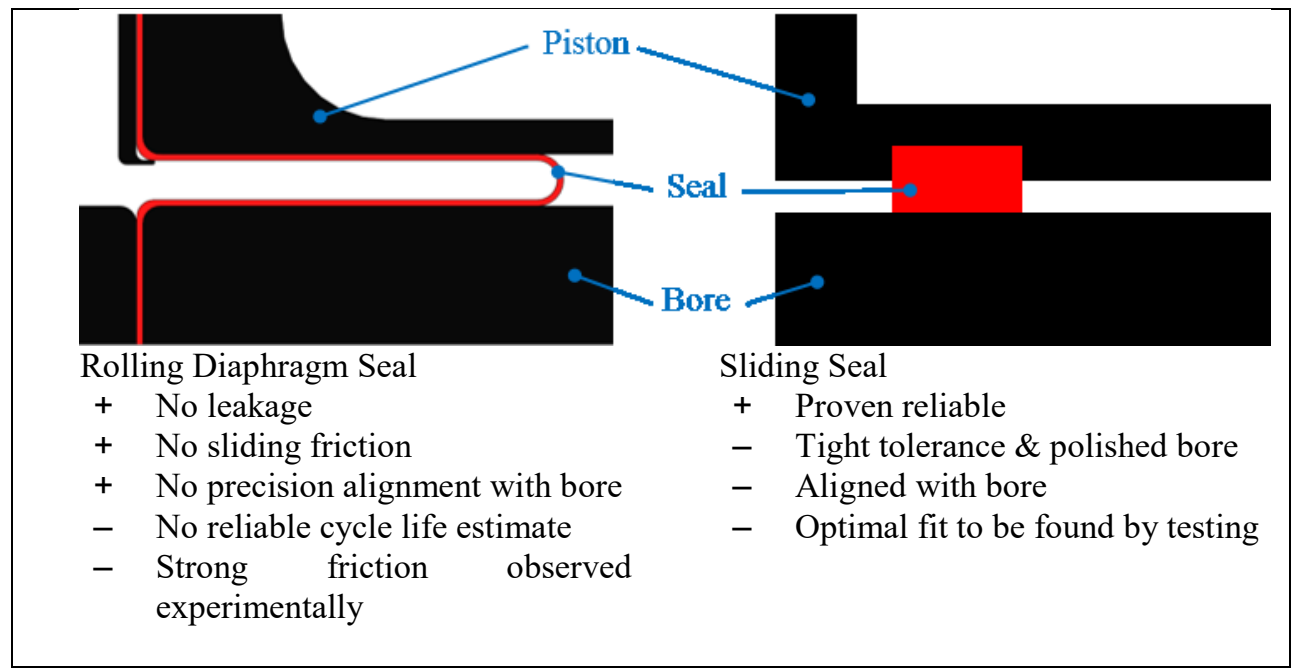

Bellows have been used as a combined power piston cylinder and seal [5], but their low strength limits them to atmospheric engines with a small pressure swing.

Rolling diaphragm seals or 'roll socks' rely on deformation rather than a sliding contact and could potentially circumvent the problems of sliding seals. As shown in Table 4 (left), these diaphragms form a convolution between piston and bore, and can cover a large gap without any leakage and without requiring precise alignment with the bore or a particular surface finish. A piston with a rolling diaphragm seal can be aligned with and guided by a central rod, making the central guide rod concept possible.

Utilizing these benefits, the early design phase of the 2021 prototype was based around using a rolling diaphragm piston seal. The power piston diameter and stroke were chosen because one of the largest diaphragms available from the manufacturer [14] (Art. 4-1200600-1125) has a swept volume of $17.5 \mathrm{~L}$, which is close to the size estimate from isothermal analysis (section 2.1.4). However, it was decided not to proceed with this seal because of lacking information about its reliability:

- Rolling diaphragms are common in small size, low frequency applications such as valves and linear actuators. A 12 -inch $(305 \mathrm{~mm})$ piston at $f=1 \mathrm{~Hz}$ is a large-scale, high-cycle application for which there is little knowledge about the cycle life of diaphragms.

- Manufacturer cannot confidently say that 100,000 cycles would be achievable [15]. That is equal to about 28 hours of engine runtime before the seal would be expected to fail.

- Considering the duration of engine experiments including warm-up, and the possibility of the seal failing earlier, it would be too risky to base the engine design around a component that comes with such uncertainties.

- The author tested a small $(2.5 \mathrm{inch} / 64 \mathrm{~mm})$ rolling seal and observed unexpectedly strong friction from stretching of the elastomer material. Rolling diaphragm friction may generally be higher than expected by authors.

- A commercially successful Stirling engine company was unable to develop a reliable machine with rolling diaphragm due to issues with fatigue and pressure containment [13].

- However, Philips in the 1960 s achieved a lifetime of 10,000 hours at 1500 rpm in engines of the kilowatt scale with similar seals [16]. 
Experimental testing of large rolling diaphragms in piston engines needs to be carried out to research their viability for LTDSEs and similar applications. If they can be made reliable, rolling seals could become a key component for making LTDSEs economical.

The design of the sliding seal is work in progress. Several configurations of low friction sliding seals will be tested at small scale before a design will be selected for the prototype.

\subsection{Heat Exchanger Module}

The heat exchanger modules are only roughly defined in their structure and outer dimensions as of June 2021. As shown in Figure 7, one module is a sandwiched stack of rectangular cross section heat exchangers, which will most likely be one intercooler core each, with a regenerator section made of a thermal insulating material in between them. Each core has an internal volume of $\sim 10 \mathrm{~L}$. There will most likely be two modules mounted beside the cylinder as seen in Figure 3. The regenerator material and porosity can be varied to analyze if the numerical model predicts the effectiveness and flow friction of different regenerator setups correctly.

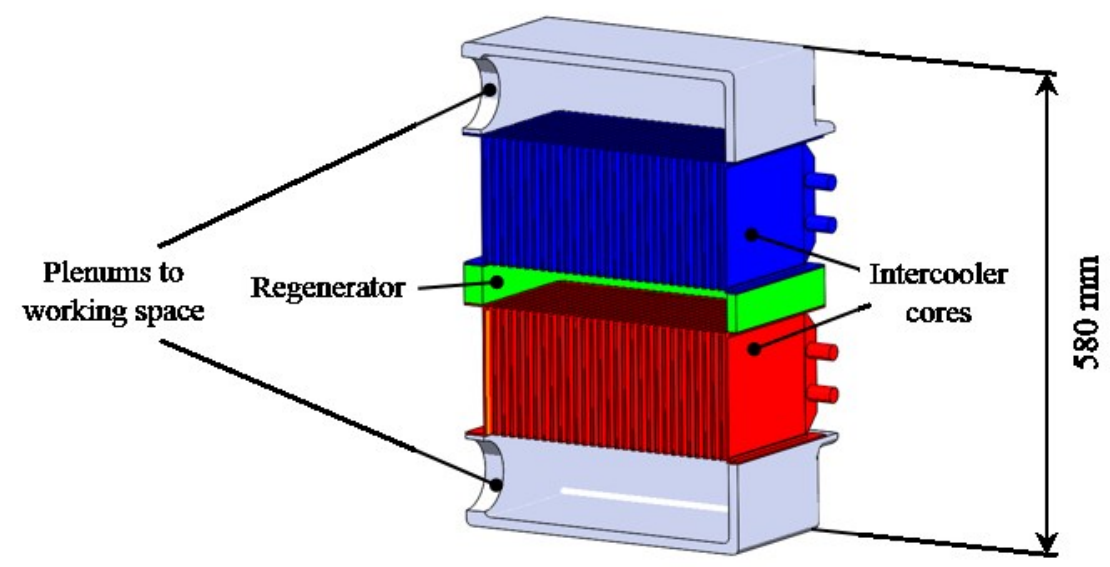

Figure 7: Cross section view of heat exchanger module.

\section{Conclusion}

A low temperature difference Stirling engine prototype is being developed with a target shaft power of $100 \mathrm{~W}$ at atmospheric charge pressure and source/sink temperatures of $95^{\circ} \mathrm{C} / 5^{\circ} \mathrm{C}$. The main objective is to produce data for the validation of a numerical model which was developed to predict the characteristics of low temperature engines. The main goals for the design process were defined as

- Minimizing mechanical friction (mechanism, seals) and flow losses as strategy to maximize shaft power

- Variable operating parameters that allow to cover a wide range of operating conditions in a single engine. The variables are: Heat exchanger type and size through modular design, compression ratio through piston stroke variation, charge pressure between $1 \mathrm{~atm}$ and $10 \mathrm{~atm}$.

The resulting design is a beta-type machine with a total gas volume on the order of 100 liters. It features displacer and power pistons in a combined cylindrical working space and a 
mechanism using pivoting links similar to a bellcrank. The stroke of the power piston is adjustable while maintaining a constant top dead center position. Two alternatives for the power piston seal were considered, a low-friction rolling seal and a conventional sliding seal. The rolling seal offers potential advantages for low friction machines, but it is unclear whether it can achieve sufficient reliability.

As of June 2021, the design of mechanism and crankcase is completed and manufacturing will begin shortly. Remaining engine sections are in the detailed design stage.

\section{Acknowledgements}

The authors acknowledge the financial support from Future Energy Systems (FES) from the University of Alberta, the Natural Sciences and Engineering Research Council of Canada (NSERC), and Alberta Innovates.

\section{References}

1. J. Banks, N. B. Harris, "Geothermal Potential of Foreland Basins: A Case Study from the Western Canadian Sedimentary Basin”, Geothermics 76, pp. 74-92 (2018)

2. C. Speer, "A comparison between Stirling and organic Rankine cycle engines for waste heat recovery applications", International Stirling Engine Conference (ISEC) (2021)

3. C. P. Speer, "Modifications to Reduce the Minimum Thermal Source Temperature of the ST05G-CNC Stirling Engine", Thesis, University of Alberta, 2018.

4. D. A. Miller, "Experimental Investigation of Stirling Engine Modelling Techniques at Reduced Source Temperatures", Thesis, University of Alberta, 2019.

5. C. J. A. Stumpf, "Parameter Optimization of a Low Temperature Difference GammaType Stirling Engine to Maximize Shaft Power", Thesis, University of Alberta, 2018.

6. M. Nicol-Seto, "Investigation of Drive Mechanism Modification to Increase Thermodynamic Performance of a Low Temperature Difference Gamma Stirling Engine", Thesis, University of Alberta, 2021. Unpublished.

7. M. Nicol-Seto, "Experimental evaluation of piston motion modification to improve the thermodynamic power output of a low temperature gamma Stirling engine", International Stirling Engine Conference (ISEC) (2021)

8. J. P. Michaud, "Low Temperature Difference Alpha-Type Stirling Engine for the Experimental Determination of Optimal Parameters to Maximize Shaft Power", Thesis, University of Alberta, 2020.

9. S. M. W. Middleton, "A modular numerical model for Stirling engines and single-phase thermodynamic machines", Thesis, University of Alberta, 2021.

10. J. R. Senft, "Mechanical Efficiency of Heat Engines", Cambridge University Press, 2007.

11. J. R. Senft, V. J. Senft, "Bellcrank Mechanisms for Stirling Engines", IECEC 96 Proceedings of the 31st Intersociety Energy Conversion Engineering Conference (1996)

12. A. Ross, "Making Stirling Engines", $3^{\text {rd }}$ edition, Andy Ross (1997)

13. S. P. Weaver, Cool Energy Inc., Personal conversation (2021)

14. Bellofram Corp., "Bellofram Design Manual", https://www.belloframdiaphragm.com/diaphragm-literature

15. Bellofram Corp., Personal conversation (2021)

16. G. Walker, "Stirling Engines", pp. 300ff., Clarendon Press (1980) 